\title{
Metabolic profiling identifies trehalose as an abundant and diurnally fluctuating metabolite in the microalga Ostreococcus tauri
}

\author{
Matthias Hirth $^{1} \cdot$ Silvia Liverani $^{2} \cdot$ Sebastian Mahlow $^{1} \cdot$ François-Yves Bouget $^{3}$ • \\ Georg Pohnert $^{4,5} \cdot$ Severin Sasso $^{1}$
}

Received: 12 January 2017 / Accepted: 31 March 2017 / Published online: 17 April 2017

(c) The Author(s) 2017. This article is an open access publication

\begin{abstract}
Introduction The picoeukaryotic alga Ostreococcus tauri (Chlorophyta) belongs to the widespread group of marine prasinophytes. Despite its ecological importance, little is known about the metabolism of this alga.

Objectives In this work, changes in the metabolome were quantified when $O$. tauri was grown under alternating cycles of $12 \mathrm{~h}$ light and $12 \mathrm{~h}$ darkness.

Methods Algal metabolism was analyzed by gas chromatography-mass spectrometry. Using fluorescence-activated cell sorting, the bacteria associated with $O$. tauri were depleted to below $0.1 \%$ of total cells at the time of metabolic profiling.

Results Of 111 metabolites quantified over light-dark cycles, 20 (18\%) showed clear diurnal variations. The strongest fluctuations were found for trehalose. With an intracellular concentration of $1.6 \mathrm{mM}$ in the dark, this
\end{abstract}

Electronic supplementary material The online version of this article (doi:10.1007/s11306-017-1203-1) contains supplementary material, which is available to authorized users.

Severin Sasso

severin.sasso@uni-jena.de

1 Institute of General Botany and Plant Physiology, Friedrich Schiller University, Jena, Germany

2 Department of Mathematics, Brunel University London, Uxbridge, UK

3 Sorbonne Universités, UPMC Univ Paris 06 \& Centre National pour la Recherche Scientifique CNRS, UMR 7621, Laboratoire d'Océanographie Microbienne, Observatoire Océanologique, Banyuls-sur-Mer, France

4 Institute for Inorganic and Analytical Chemistry, Friedrich Schiller University, Jena, Germany

5 Max Planck Institute for Chemical Ecology, Jena, Germany disaccharide was six times more abundant at night than during the day. This fluctuation pattern of trehalose may be a consequence of starch degradation or of the synchronized cell cycle. On the other hand, maltose (and also sucrose) was below the detection limit $(\sim 10 \mu \mathrm{M})$. Accumulation of glycine in the light is in agreement with the presence of a classical glycolate pathway of photorespiration. We also provide evidence for the presence of fatty acid methyl and ethyl esters in $O$. tauri.

Conclusions This study shows how the metabolism of $O$. tauri adapts to day and night and gives new insights into the configuration of the carbon metabolism. In addition, several less common metabolites were identified.

Keywords Microalgae $\cdot$ Picoeukaryotes $\cdot$ Carbon metabolism · Untargeted metabolomics · pantothenate.

\section{Introduction}

Photosynthesis has profoundly changed life on Earth and is vitally important for all aerobic organisms today. In the world oceans, phytoplankton is responsible for the fixation of $45-50$ gigatons of carbon per year (Falkowski et al. 1998). Aquatic photosynthesis is at the origin of the fossil fuels we exploit today, and at the same time contributes to the sequestration of carbon from the atmosphere (Falkowski et al. 1998). Understanding the life of photosynthetic organisms is pivotal for a description of microbial communities, food webs and biogeochemical cycles (Worden et al. 2015).

Marine picoeukaryotes, which have a diameter of $2 \mu \mathrm{m}$ and less, make significant contributions to primary production in coastal and oligotrophic waters ( $\mathrm{Li} \mathrm{1994;} \mathrm{Worden}$ et al. 2004). Owing to their large surface area/volume 
ratios, picoeukaryotes have a competitive advantage over larger cells at low external concentrations of nutrients (Falkowski et al. 1998). Among the picophytoplankton, the order Mamiellales contains several cosmopolitan genera including Ostreococcus, Micromonas, and Bathycoccus (Vaulot et al. 2008). These Mamiellophyceae (Chlorophyta) represent a phylogenetically deep-branching class within the green lineage (Leliaert et al. 2012). While Ostreococcus tauri persists at densities of $\sim 2 \times 10^{5}$ cells ml $^{-1}$ in the Mediterranean Thau Lagoon (Chrétiennot-Dinet et al. 1995), Ostreococcus spp. have also been found in other places such as the Atlantic and Pacific Oceans, where blooms have been observed (Derelle et al. 2006; O'Kelly et al. 2003; Collado-Fabbri et al. 2011). Ostreococcus strains that were sampled from different ocean depths showed adaptations to different light intensities (Rodríguez et al. 2005).

With a tiny cell size of only $\sim 1 \mu \mathrm{m}$, the non-flagellated $O$. tauri cells feature a simple architecture with a single chloroplast and mitochondrion (Courties et al. 1994; Chrétiennot-Dinet et al. 1995). As a minimal version of a photosynthetic eukaryote, $O$. tauri has recently developed into a promising model organism of fundamental biology, and a variety of processes have been investigated including evolution (Blanc-Mathieu et al. 2013), viral infection (Derelle et al. 2008), photosynthesis (Cardol et al. 2008), light sensing (Heijde et al. 2010; Djouani-Tahri et al. 2011a), circadian rhythm (Corellou et al. 2009; O'Neill et al. 2011), cell division (Moulager et al. 2010), nutrient uptake (Botebol et al. 2015; Lelandais et al. 2016), fatty acid biosynthesis (Vaezi et al. 2013), and the regulation of starch metabolism (Sorokina et al. 2011). So far, O. tauri has only been observed in the form of haploid cells (Corellou et al. 2009; Grimsley et al. 2010). Its sequenced genome has a size of merely $12.6 \mathrm{Mb}$, accompanied by a decreased gene redundancy compared to the genomes of land plants (Derelle et al. 2006). In version 2, the genome sequence of $O$. tauri was improved by additional Illumina DNA and RNA sequencing, reassembly and reannotation (Blanc-Mathieu et al. 2014). Genetic transformation of $O$. tauri is established, and a high frequency of homologous recombination in the nucleus allows for tailored genetic modifications (Corellou et al. 2009; Lozano et al. 2014).

Algae regularly interact with bacteria, and these interactions can influence the productivity of microbial communities (Hom et al. 2015; Ramanan et al. 2016). A region called the phycosphere, which surrounds an algal cell, contains a gradient of algal metabolites that can affect the growth of other microorganisms (Amin et al. 2012). Possible explanations for the often observed difficulty to obtain axenic algal cultures are metabolic interconnections or physical contact between the interacting organisms (Abby et al. 2014; Hom et al. 2015). Despite sustained efforts to remove the bacteria contained in $O$. tauri laboratory cultures (Abby et al. 2014), there are currently no axenic $O$. tauri cultures available. A recent study highlighted that $O$. tauri can obtain a thiazole-containing precursor of vitamin $\mathrm{B}_{1}$ from Marinobacter sp. (Paerl et al. 2017). Even though O. tauri is auxotrophic for $\mathrm{B}_{1}$ (Paerl et al. 2017), this auxotrophy cannot explain the hurdles to eliminate the bacteria because growth media are commonly supplemented with this vitamin. Nevertheless, the difficulties to obtain axenic cultures of $O$. tauri might be a consequence of similar yet unknown trophic interactions with associated bacteria. The bacterial community associated with the originally sequenced O. tauri strain OTTH0595, used in this work, is dominated by Marinobacter spp. ( $\gamma$-Proteobacteria) (Lupette et al. 2016; Paerl et al. 2017Lupette et al. 2016, 2017). Various other bacteria have been identified in this culture, including members of the Flavobacteriia and $\alpha-, \beta$ and $\gamma$-Proteobacteria (Abby et al. 2014).

As a tiny member of the marine plankton, O. tauri is frequently exposed to changing environmental conditions, including variable illumination due to day and night or variable solar irradiation, changes in temperature, salinity, nutrient availability, or grazing pressure. Adaptation to variable abiotic and biotic conditions is accomplished with the help of $\sim 120$ transcription factors (Weirauch et al. 2014). So far, no experimental studies have systematically explored $O$. tauri's metabolism, and its integration into the cell's regulatory networks is incompletely understood. As a first step to describe the metabolism of this minimalist photosynthetic eukaryote, we applied untargeted quantitative metabolic profiling to $O$. tauri grown under light-dark cycles. Our strategy, which is based on gas chromatography-mass spectrometry (GC-MS), provides new insights particularly into the primary metabolism of this alga.

\section{Materials and methods}

\subsection{Solvents and standard compounds}

The following solvents were used for extraction and derivatization of metabolites: chloroform (Product no. 83626.290, VWR, Darmstadt, Germany), ethanol (1.11727.1000, VWR), methanol (34860, Sigma-Aldrich, Munich, Germany), and pyridine (270407, Sigma-Aldrich). Standard compounds are listed in Supplementary Table 1.

\subsection{Cultivation of Ostreococcus tauri}

Ostreococcus tauri OTTH0595, which is sometimes called OTH95 (Courties et al. 1994; Derelle et al. 2006), was used for all experiments. RCC745 refers to the same strain, while RCC4221 is derived from it (Abby et al. 2014). O. tauri was cultivated in artificial sea water (ASWO 
medium), which is a modified Keller medium (DjouaniTahri et al. 2011b). In addition to Keller trace metal solution (Keller et al. 1987), ASWO medium contains $420 \mathrm{mM}$ $\mathrm{NaCl}, 10 \mathrm{mM} \mathrm{KCl}, 20 \mathrm{mM} \mathrm{MgCl} 2,10 \mathrm{mM} \mathrm{CaCl}_{2}, 25 \mathrm{mM}$ $\mathrm{MgSO}_{4}, 2.5 \mathrm{mM} \mathrm{NaHCO}{ }_{3}, 0.88 \mathrm{mM} \mathrm{NaNO}_{3}, 5.0 \times 10^{-5} \mathrm{M}$ $\mathrm{NH}_{4} \mathrm{Cl}, 1.0 \times 10^{-5} \mathrm{M} \beta$-glycerophosphate, $1.0 \times 10^{-8} \mathrm{M}$ $\mathrm{H}_{2} \mathrm{SeO}_{3}, 1 \mathrm{ml}$ of $1 \mathrm{M}$ Tris- $\mathrm{HCl}(\mathrm{pH}$ 7.2) per liter of medium, $3.7 \times 10^{-10} \mathrm{M}$ cyanocobalamin, $2.0 \times 10^{-9} \mathrm{M}$ biotin, and $3.0 \times 10^{-7} \mathrm{M}$ thiamine. For metabolic profiling, 42 Erlenmeyer flasks $(500 \mathrm{ml})$ containing $200 \mathrm{ml}$ of ASWO medium each were inoculated to a cell density of $0.27 \times 10^{6}$ cells $\mathrm{ml}^{-1}$. Cultures were incubated under alternating light-dark cycles, consisting of $12 \mathrm{~h}$ of blue light followed by $12 \mathrm{~h}$ of darkness, at a temperature of $19.0 \pm 0.3^{\circ} \mathrm{C}$. Blue light of a final photosynthetic photon flux density of $10.6 \pm 0.9 \mu \mathrm{mol}$ photons $\mathrm{m}^{-2} \mathrm{~s}^{-1}$ was generated by passing white light (Philips Master TL-D 36 W 865 lamps) through a blue filter (Lee Filter Roll 183 Moonlight Blue, Thomann, Burgebrach, Germany). Cultures were agitated manually once a day.

\subsection{Antibiotic treatment}

In an attempt to remove bacteria from $O$. tauri cultures, ASWO medium containing $310 \mu \mathrm{g} \mathrm{ml}^{-1}$ penicillin $\mathrm{G}$ (P3032, Sigma-Aldrich), $1.9 \mu \mathrm{g} \mathrm{ml} \mathrm{m}^{-1}$ chloramphenicol (C1919, Sigma-Aldrich), $1.4 \mu \mathrm{g} \mathrm{ml}^{-1}$ polymyxin B (P4932, Sigma-Aldrich), and $2.3 \mu \mathrm{g} \mathrm{ml}^{-1}$ neomycin (N1142, Sigma-Aldrich) was inoculated with O. tauri. After cultivation for 1 day, $220 \mu \mathrm{g} \mathrm{ml}^{-1}$ cefotaxime (C7039, Sigma-Aldrich) and $500 \mu \mathrm{g} \mathrm{ml}^{-1}$ carbenicillin (C3416, Sigma-Aldrich) were added. After six further days, the grown culture was used to inoculate fresh ASWO medium without antibiotics, and after several rounds of subcultivation, the bacterial content was quantified by analytical flow cytometry. A single antibiotic treatment decreased the number of bacteria in $O$. tauri cultures for several months, but was unable to remove them completely.

\subsection{Flow cytometry}

To quantify algal and bacterial cells in $O$. tauri mixed cultures, aliquots of cells were fixed for $30 \mathrm{~min}$ with $0.25 \%$ (v/v) glutaraldehyde (3778.1, Carl Roth, Karlsruhe, Germany) at room temperature and stored at $-20^{\circ} \mathrm{C}$ until analysis. After thawing, SYBR Green I (S7563, Thermo Fisher Scientific, Darmstadt, Germany) was added to a $1 \times$ final concentration together with a defined number of counting beads (C36950, Thermo Fisher Scientific) for absolute quantification. A FACSCalibur flow cytometer (BD Biosciences) was used to analyze algal and bacterial cells using channels FL1 (530/30) and FL3 (670LP), and the counting beads using channels FL2 (585/42) and FL4 (661/16).
Thresholds were adjusted to reduce background events in the FL1 and FL3 channels. For data analysis, the software Cell Quest (BD Biosciences, version 3.3) was used. The suitability of flow cytometry to quantify the density of $O$. tauri cells was verified by the parallel counting of cells using an improved Neubauer counting chamber (T729.1, Carl Roth, Karlsruhe, Germany) under a light microscope with 400-fold magnification (five technical replicates per biological replicate).

Fluorescence-activated cell sorting (FACS) of live cells was performed with a FACSAria Fusion instrument (BD Biosciences) equipped with an $85-\mu \mathrm{m}$ diameter nozzle and controlled by the program BD FACSDiva version 8.0.1. Phosphate-buffered saline (A1286301, Thermo Fisher Scientific) was used as the sheath fluid. For sorting, an $O$. tauri culture with a density of $\sim 10^{7}$ cells $\mathrm{ml}^{-1}$ and a bacterial content of $11.2 \%$ was used. Cells were selected based on a suitable population in a scatter plot of the channels FSC (488/10) and B695 (695/40). $6 \times 10^{4}$ sorted cells were spun down (5 min, $4000 \mathrm{xg}$ ) and used to inoculate a fresh culture with an initial density of $5.5 \times 10^{3}$ cells ml ${ }^{-1}$ in ASWO medium. After several rounds of subcultivation, the bacterial content was reassessed by analytical flow cytometry.

\subsection{Acquisition of metadata (inorganic nutrients, $\mathrm{pH}$ )}

Fifty millilitres of culture were sterile-filtered, frozen and sent to the GEOMAR Helmholtz Centre for Ocean Research in Kiel (Germany). After thawing, samples were tenfold diluted with $\mathrm{NaCl}$ solution (salinity of 36) and measured in triplicates. Nitrate, nitrite and ammonium were determined photometrically (Hansen and Koroleff 1999). As a standard, a solution containing $80 \mu \mathrm{M}$ nitrate, $2.0 \mu \mathrm{M}$ nitrite and $5.0 \mu \mathrm{M}$ ammonium was used. $\mathrm{pH}$ was determined with digital $\mathrm{pH}$ meter pH525 equipped with electrode SenTix 21 (WTW, Weilheim, Germany).

\subsection{Metabolite sampling and derivatization}

To sample $O$. tauri metabolites, we largely followed a previously established protocol (Vidoudez and Pohnert 2012): Cells were collected by filtration of $150 \mathrm{ml}$ of culture through a pre-washed Whatman GF/F filter (Z242519, Sigma-Aldrich) under reduced pressure (800 mbar). The cells were lysed by addition of $3.5 \mathrm{ml}$ of extraction mix optimized for microalgae (methanol:ethanol:chloroform 2:6:2, Vidoudez and Pohnert 2012) and incubation for $5 \mathrm{~min}$ at room temperature. For time points during darkness, sampling was performed under green light. As a negative control, $150 \mathrm{ml}$ of ASWO medium were filtered, the filter washed with extraction mix, and the resulting sample processed in the same way as the main samples. Extracts were stored at $-80^{\circ} \mathrm{C}$ until further use. 
For derivatization, insoluble material was removed by centrifugation $\left(16,000 \times \mathrm{g}, 4^{\circ} \mathrm{C}, 5 \mathrm{~min}\right)$, and $20 \mathrm{nmol}$ of ribitol (internal standard) were added to a volume equivalent of $4.8 \times 10^{9}$ cells (as determined by flow cytometry). After samples were dried at 50 mbar in a desiccator, the residues were dissolved in $100 \mu \mathrm{l}$ pyridine containing $2 \mathrm{mg}$ of methoxyamine hydrochloride (226904, Sigma Aldrich) and vortexed for $1 \mathrm{~min}$. Samples were incubated at $60^{\circ} \mathrm{C}$ for $1 \mathrm{~h}$, then at room temperature for $17 \mathrm{~h}$. For the second derivatization step, $40 \mu$ of retention index mix (decane, pentadecane, nonadecane, octacosane, dotriacontane all $1 \mathrm{mM}$, and hexatriacontane $0.5 \mathrm{mM}$ in hexane, all $>99 \%$, Sigma-Aldrich) were added to $1 \mathrm{ml}$ of $N$-methyl- $N$ (trimethylsilyl)trifluoroacetamide (MSTFA, 701270, Macherey-Nagel, Düren, Germany), and $50 \mu$ l of this mixture were added to $50 \mu \mathrm{l}$ of sample and incubated at $40^{\circ} \mathrm{C}$ for $1 \mathrm{~h}$. Afterwards, the samples were centrifuged $(3000 \times g$, $4^{\circ} \mathrm{C}, 10 \mathrm{~min}$ ), and the supernatant analyzed by GC-MS.

\subsection{GC-MS}

Samples were analyzed in random order on a TRACE Ultra gas chromatograph (Thermo Scientific) equipped with an AS3000 II auto sampler and a DB-5MS Agilent column (30 mx $0.250 \mathrm{~mm} \times 0.25 \mu \mathrm{m}$ ) with a $10 \mathrm{~m}$ Duraguard precolumn. The GC was connected to an ISQ Single Quadrupole mass spectrometer (Thermo Scientific). For each batch of 20 samples, a new deactivated glass liner $(5 \mathrm{~mm}$ inner diameter, $8 \mathrm{~mm}$ outer diameter, $105 \mathrm{~mm}$ length; Thermo Scientific) with glass wool was used. Liners were shipped to CS-Chromatographie Service (Langerwehe, Germany) for cleaning and deactivation (GW INNO-Sil Plus). $1 \mu \mathrm{l}$ of sample was injected at $300^{\circ} \mathrm{C}$ and analyzed in split mode 10. The oven temperature was kept at $60^{\circ} \mathrm{C}$ for $1 \mathrm{~min}$, then increased by $15^{\circ} \mathrm{C} \mathrm{min}^{-1}$ to $310^{\circ} \mathrm{C}$ and kept at $310^{\circ} \mathrm{C}$ for $10 \mathrm{~min}$. The flow rate of the helium 5.0 carrier gas was set to $1 \mathrm{ml} \mathrm{min}{ }^{-1}$. Ionization and fragmentation was performed by an electron impact source at $70 \mathrm{eV}$ and $280^{\circ} \mathrm{C}$. Five MS scans per second were recorded with a resolution of 866 at $m / z$ 502.20 (FWHM=0.53).

\subsection{Data processing, quantification of metabolites, and data analysis}

GC-MS data files (*.raw) were converted to *.cdf files using the file converter of Xcalibur 2.2.44 (Thermo Scientific). The remaining data processing was done as described by Vidoudez and Pohnert 2012, with the following modifications/details: AMDIS version 2.70 (http://www.amdis. net) was used, and component width was set to 12 ; version 2.08 of program MET-IDEA (Broeckling et al. 2006) was used with the parameter MS type: quadrupole. The resulting datasets were imported into Excel 2010 (Office 2010,
Microsoft, Redmont, USA). Using extracted ion chromatograms (EICs) of model ions provided by AMDIS, peak areas were normalized by the peak area of the internal standard ribitol $(\mathrm{m} / \mathrm{z}, 103.1$ at $11.66 \mathrm{~min})$. Peaks were further considered only if they were present in all samples, and if their intensities were at least fivefold over background. For this purpose, the average peak area was compared to the fivefold average peak area of the negative controls. The resulting data were double-checked to eliminate errors in peak integration and redundant model ions that originate from the same compound. Bayesian Fourier clustering of temporal metabolite patterns was performed as described previously for transcript patterns (Monnier et al. 2010).

\subsection{Identification of metabolites}

For each quantified metabolite, mass spectra at the peak maximum of the EIC were background-corrected using a region adjacent to the peak in the same EIC. The resulting spectrum was compared with mass spectra deposited in the NIST/EPA/NIH Mass Spectral Library version 2011 using the software MS Search (version 2.0d from 2005; http:// chemdata.nist.gov/mass-spc/ms-search). The identification of selected metabolites was verified with the help of retention indices and mass spectra of authentic standards (Supplementary Table 1) analyzed under identical conditions. Platform-independent retention indices were determined with the help of the retention times of the unknown metabolite and those of two alkanes in the retention index mix (cf. Sect. 2.5) that elute before and after the unknown metabolite. To calculate non-isothermal retention indices, the following equation derived from Lee et al. 1979 was used:

$I=100\left[n+(N-n) \frac{t_{r}(\text { unknown })-t_{r}(n)}{t_{r}(N)-t_{r}(n)}\right]$

where $I$ is the retention index, $n$ is the number of carbon atoms of the alkane eluting earlier, $N$ is the number of carbon atoms of the alkane eluting later, and $t_{\mathrm{r}}$ is the retention time. The unknown metabolite was considered identical with the authentic standard if their retention indices differed by no more than five units, and the mass-spectral match value was at least 700 .

For the identification of trehalose in $O$. tauri, metabolites were extracted as described in Sect. 2.5, but using $200 \mathrm{ml}$ of a 9-day old culture $\left(\sim 10^{10}\right.$ cells). The dried extract was dissolved in $2 \mathrm{ml} 20 \mathrm{mM}$ potassium phosphate buffer, $\mathrm{pH}$ 6.0. For comparison, $100 \mathrm{nmol}$ of trehalose, maltose or glucose (supplemented with internal standard) were used (Supplementary Table 1). Samples were incubated with 0.08 units of maltase (G9259-100UN, Sigma-Aldrich) or trehalase (E-TREH, Megazyme, Bray, Ireland) for $1 \mathrm{~h}$ 
at $37^{\circ} \mathrm{C}$. Reactions were quenched by addition of $2 \mathrm{ml}$ of chloroform followed by $10 \mathrm{~s}$ of vortexing. The aqueous phase was dried under nitrogen gas, and samples were derivatized and analyzed as described in Sects. 2.5 and 2.6.

\section{Results}

\subsection{Flow-cytometric analysis of $O$. tauri cultures}

As a first step towards the metabolic profiling of the marine microalga $O$. tauri, we used flow cytometry to simultaneously quantify the cell densities of algae and bacteria present in the same culture. For this purpose, cells were fixed with glutaraldehyde and stained with the DNA-binding dye SYBR Green I (see Sect. 2 for details). Samples were then analyzed by flow cytometry using one channel that detects SYBR Green I fluorescence, and one channel that detects chlorophyll fluorescence (Fig. 1a). In the resulting flow cytogram, $O$. tauri cells are represented by events that show high levels of both chlorophyll and bound SYBR Green I, while non-photosynthetic cells (mostly bacteria) only show a high amount of SYBR Green I (Fig. 1a).

Algal densities obtained by flow cytometry correlated well with values obtained by hemocytometry (Fig. 1b). Quantification by flow cytometry was applicable to cell densities between $1.2 \times 10^{6}$ and $2.9 \times 10^{7}$ cells $\mathrm{ml}^{-1}$ (Fig. 1b), covering a dynamic range of at least 25-fold.

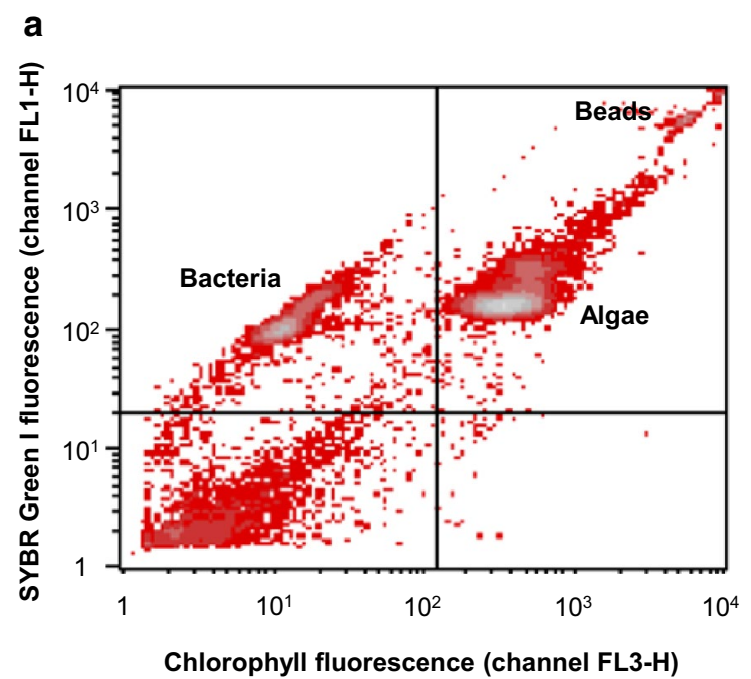

Fig. 1 Quantification of cell density and bacterial content of $O$. tauri cultures by flow cytometry. a Example of a flow cytogram of an $O$. tauri culture (density plot). For illustration, a sample with a significant portion of bacteria (20\%) is shown. b Cell densities obtained by flow cytometry compared to cell densities obtained by hemocytometer counting of different dilutions of 16-day old $O$. tauri cultures. In both cases, total cells were counted. For the flow-cytometric meas-
This experiment confirms previous studies (ChrétiennotDinet et al. 1995; Moulager et al. 2010) that flow cytometry is a suitable method to quantify the cell density of $O$. tauri cultures quickly and reliably, and it shows how algal and bacterial cells can be distinguished.

There are currently no axenic $O$. tauri cultures available. We thus attempted to establish such a culture using a cocktail of six different antibiotics (see Sect. 2), but failed to remove the bacteria completely. As an alternative strategy to obtain an axenic culture, fluorescence-activated cell sorting (FACS) was applied to an O. tauri culture not previously treated with antibiotics. While the complete removal of bacteria was impossible, FACS successfully depleted the bacteria from $\sim 10 \%$ to below $1 \%$ (values indicate the number of bacteria relative to the total number of cells). This bacterial content appeared sufficiently low to exclude substantial effects of the bacteria on the metabolic profile. As a consequence of FACS sorting, the bacterial content remained low throughout the metabolic profiling experiment (see below).

\subsection{Metabolic profiling: experimental design and collection of metadata}

Ostreococcus isolates have been found in waters from a variety of depths and trophic states. The $O$. tauri isolate OTTH0595 used in this study originates from surface waters of a shallow Mediterranean lagoon and is able to acclimate to a wide range of light intensities (Rodríguez

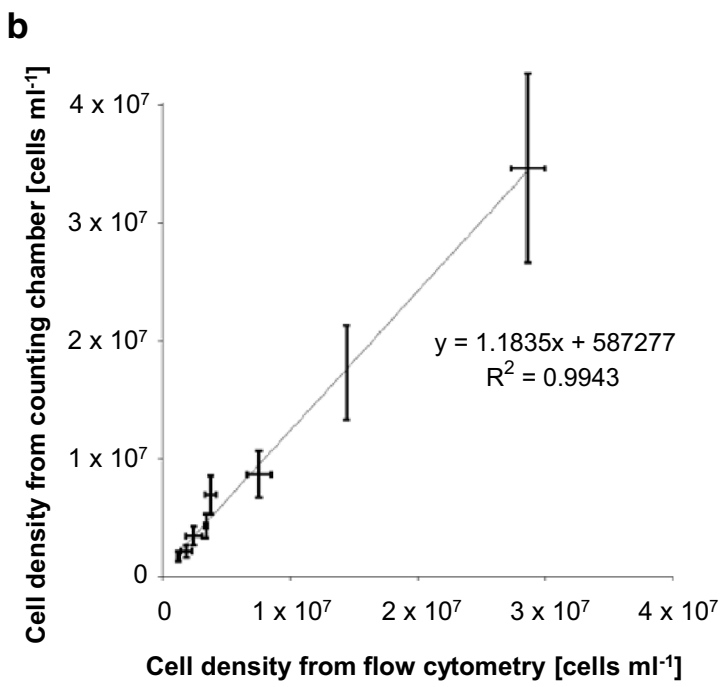

urements, samples with the indicated cell densities were prepared with ASWO medium, and two technical replicates were counted. For hemocytometry, three independent biological samples with a cell density of $\sim 7 \times 10^{6}$ cells $\mathrm{ml}^{-1}$ were counted (using five technical replicates per biological replicate), and the cell densities of the remaining samples were calculated. Mean \pm standard deviation is shown 
et al. 2005). To monitor how the metabolism of $O$. tauri responds to changing light conditions, algae were grown under $12 \mathrm{~h}$ light-12 h dark cycles, and metabolites were sampled every $4 \mathrm{~h}$ during late exponential/early stationary phase (Fig. 2a). In parallel, a variety of metadata were sampled to characterize the basic growth conditions during this experiment. $O$. tauri cultures reached early stationary phase after 7 days, and from then onwards, the cell density stayed relatively constant $\left(\sim 5\right.$ to $6 \times 10^{7}$ cells $\left.\mathrm{ml}^{-1}\right)$ until the end

\section{a Cell density and sampling scheme}
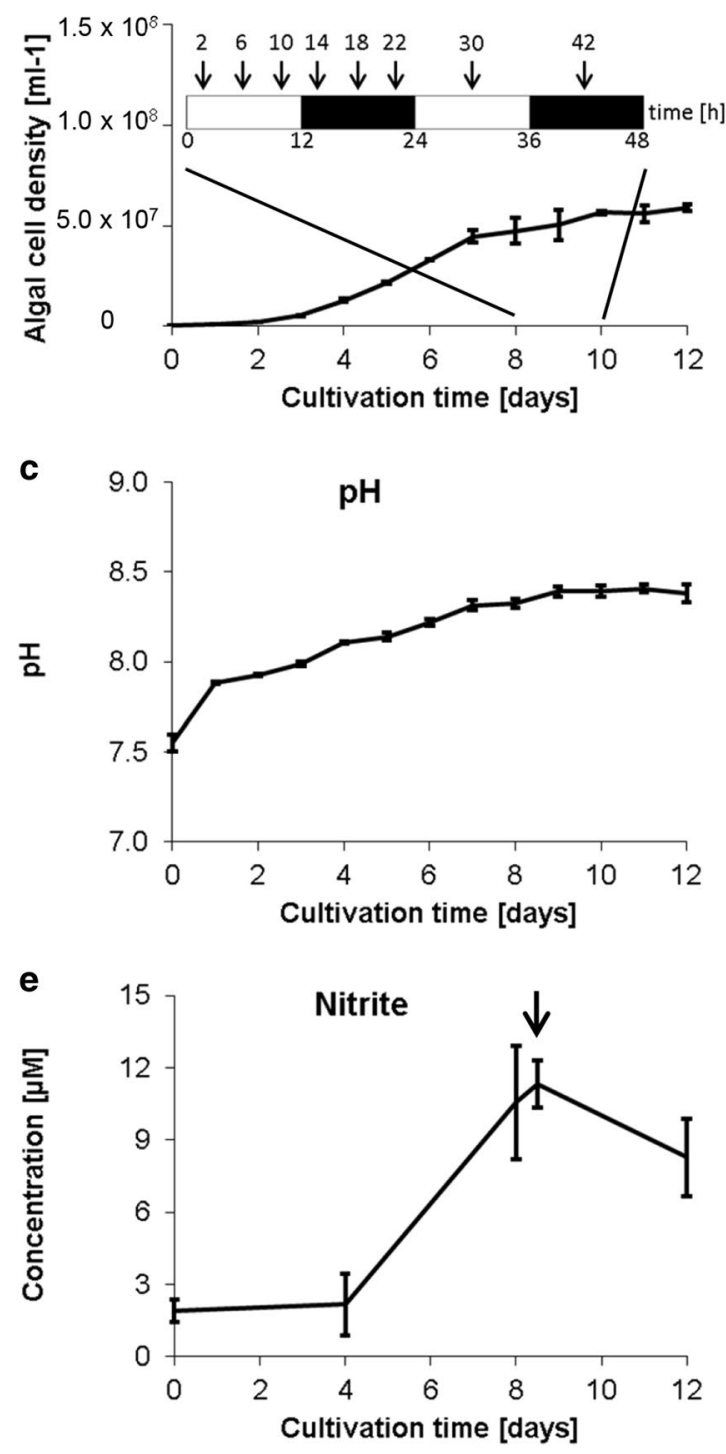

Fig. 2 Experimental design for metabolic profiling of $O$. tauri under $12 \mathrm{~h}$ light: $12 \mathrm{~h}$ dark conditions and collection of metadata. a Time points for the sampling of intracellular metabolites (arrows) and growth curve. To quantify algal cell density, samples were taken in the middle of the day (LD6). Note that data collected for an additional time point $(42 \mathrm{~h})$ were discarded due to normalization problems. b-f Other metadata collected over the course of the experi- of the experiment (Fig. 2a). During the cultivation period of 12 days, the bacterial content briefly peaked at $\sim 1.0 \%$ 2 days after inoculation before dropping back below $0.1 \%$. During the time of metabolite sampling (between days 8 and 10), the bacterial values were between 0.02 and $0.06 \%$ (Fig. 2b). pH slowly but continuously increased from 7.9 at day 1 to 8.4 at day 12 (Fig. 2c). It appears that the algae used ammonium as their major nitrogen source during the first $\sim 4$ days before they switched to nitrate, as judged from
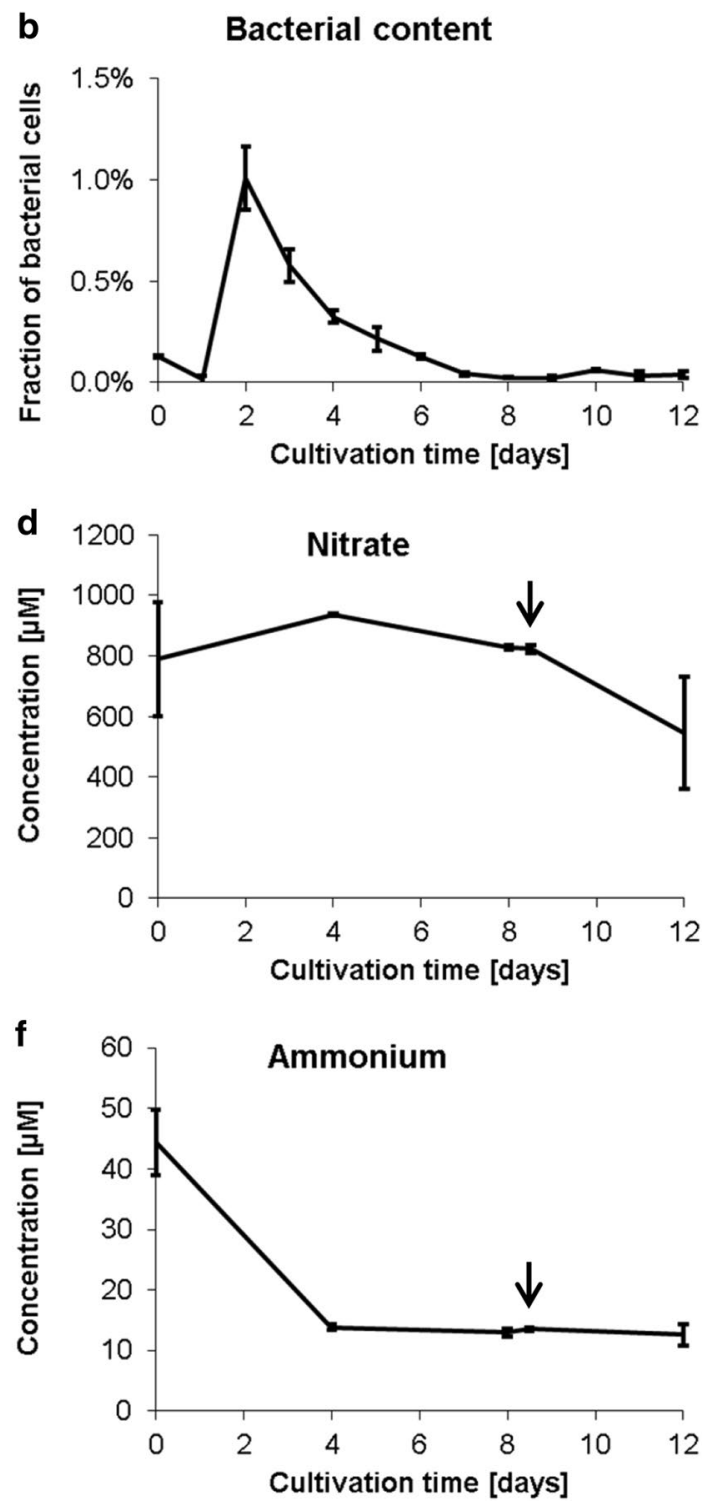

ment including bacterial content of $O$. tauri cultures (b), $\mathrm{pH}(\mathbf{c})$, and the concentrations of nitrate (d), nitrite (e), and ammonium (f). The samples were taken in the middle of the day (LD6) except the time point marked by an arrow, which was taken in the middle of the night (LD18). Mean \pm standard deviation of biological triplicates is shown (except for $\mathrm{t}=1$ day and 2 days in $(\mathbf{a}-\mathbf{c})$, and $\mathrm{t}=0$ in $(\mathbf{d}-\mathbf{f})$, where duplicates where measured) 
the decrease in nitrate that started on day 4 (Fig. 2d), a concomitant increase in nitrite (Fig. 2e), and the decrease in ammonium that leveled off after day 4 (Fig. 2f).

\subsection{Profiling and identification of $O$. tauri metabolites}

For metabolic profiling, extracts of $O$. tauri cells were derivatized with methoxyamine hydrochloride and $N$-methyl- $N$ (trimethylsilyl)trifluoroacetamide (MSTFA) and analyzed by GC-MS (see Sect. 2). Deconvolution of individual peaks in total ion current (TIC) chromatograms using program AMDIS (http://www.amdis.net) yielded a list of model ions for the detected compounds. For these model ions, EICs were generated, and the resulting peaks were quantified with the help of program MET-IDEA (Broeckling et al.
2006). Peak areas were normalized using ribitol added as an internal standard to each extract sample. After manual curation, data processing yielded 111 quantifiable peaks with intensities at least fivefold over background. While the majority of these 111 peaks correspond to distinct algal metabolites, a few peaks may correspond to alternative derivatization products derived from the same algal metabolite. For example, metabolites \#6 and \#11 (Table 1) are both derived from proline, carrying one and two trimethylsilyl modifications, respectively.

To identify metabolites, the corresponding spectra were compared to spectra deposited in the NIST/EPA/ NIH Mass Spectral Library (file NIST11_MSMS_2012. iso) using program MS Search (version 2.0d, http://chemdata.nist.gov/mass-spc/ms-search). 74 tentatively identified

Table 1 Overview of intracellular metabolites identified in $O$. tauri and confirmed with the help of authentic standards

\begin{tabular}{|c|c|c|c|c|c|}
\hline $\begin{array}{l}\text { Metabolite } \\
\text { number }\end{array}$ & Metabolite & Class & Retention index ${ }^{a}$ & $\mathrm{~m} / \mathrm{z}$ of model ion & Match value $^{b}$ \\
\hline 3 & alanine & amino acid & 1102 & 116.2 & 836 \\
\hline 6 & proline $^{\mathrm{c}}$ & amino acid & 1188 & 129.0 & 821 \\
\hline 7 & 3-chloro-1,2-propanediol & glycerol derivative & 1192 & 116.0 & 728 \\
\hline 11 & proline $^{c}$ & amino acid & 1307 & 142.1 & 920 \\
\hline 12 & glycine & amino acid & 1314 & 174.2 & 766 \\
\hline 14 & glycerate & sugar acid & 1332 & 189.0 & 761 \\
\hline 16 & pyrrole 2-carboxylate & heteroaromatic carboxylic acid & 1358 & 240.0 & 836 \\
\hline 20 & $\beta$-alanine & amino acid & 1429 & 248.0 & 828 \\
\hline 22 & pyroglutamate $^{\mathrm{d}}$ & amino acid & 1518 & 156.1 & 893 \\
\hline 27 & threonate & sugar acid & 1547 & 292.2 & 924 \\
\hline 31 & proline $^{\mathrm{c}}$ & amino acid & 1582 & 142.2 & 847 \\
\hline 41 & methyl tetradecanoate & fatty acid ester & 1733 & 143.2 & 907 \\
\hline 55 & phytol $^{\mathrm{e}}$ & diterpene alcohol & 1842 & 123.1 & 930 \\
\hline 56 & phytol $^{\mathrm{e}}$ & diterpene alcohol & 1864 & 123.2 & 923 \\
\hline 57 & phytol $^{\mathrm{e}}$ & diterpene alcohol & 1882 & 109.1 & 944 \\
\hline 61 & methyl palmitate & fatty acid ester & 1929 & 143.1 & 920 \\
\hline 64 & ethyl palmitate & fatty acid ester & 2008 & 101.1 & 760 \\
\hline 71 & methyl stearidonate & fatty acid ester & 2115 & 105.0 & 924 \\
\hline 72 & methyl linolenate & fatty acid ester & 2132 & 108.1 & 865 \\
\hline 78 & phytol $^{\mathrm{e}}$ & diterpene alcohol & 2202 & 143.1 & 882 \\
\hline 80 & linolenate (C18:3) & fatty acid & 2253 & 107.2 & 902 \\
\hline 93 & methyl docosahexaenoate & fatty acid ester & 2494 & 105.0 & 909 \\
\hline 96 & 1-palmitoylglycerol & fatty acid ester & 2603 & 371.3 & 805 \\
\hline 98 & trehalose & disaccharide & 2736 & 361.1 & 909 \\
\hline 99 & squalene & triterpene & 2816 & 121.2 & 898 \\
\hline
\end{tabular}

Parent compounds of detected derivatives are listed. Metabolites were only considered if peaks were present in all samples, and if peak intensities were at least fivefold over background (see Sect. 2 for details). A full list of identified metabolites is given in Supplementary Table 1

${ }^{a}$ The retention index was calculated from average retention times of the compound of interest and the two alkanes that elute before and after it

${ }^{b}$ Match values are given for the comparison with an authentic standard analyzed on the same GC-MS instrument

${ }^{\mathrm{c}}$ The authentic standard proline yielded a set of peaks that included the peaks observed for metabolites \#6, \#11 and \#31

${ }^{\mathrm{d}}$ Pyroglutamate is formed from glutamate during GC sample injection (Vidoudez and Pohnert 2012)

${ }^{\mathrm{e}}$ The authentic standard phytol yielded a set of peaks that included the peaks observed for metabolites \#55, \#56, \#57 and \#78 
compounds with a match value higher than 600 are shown in Supplementary Table 2; of these, 31 compounds had a match value above 800 , indicative of good confidence. To increase the reliability of these identifications, a set of authentic standards (Supplementary Table 1) was run on the same GC-MS system. Of totally 53 standards, 20 compounds were present in $O$. tauri cells (Table 1), whereas 33 compounds could not be detected in algal extracts.

The compounds identified with high confidence include a variety of amino acids, fatty acid esters and other primary metabolites (Table 1). In agreement with the notion that plants are capable of pantothenate (vitamin $\mathrm{B}_{5}$ ) biosynthesis (Smith et al. 2007), $\beta$-alanine (metabolite \#20) was detected in $O$. tauri. This is further supported by the presence of genes for ketopantoate hydroxymethyltransferase (ostta02g02520) and pantothenate synthetase (ostta09g02630). The function of threonate (\#27), which we also identified in $O$. tauri, is poorly understood, but this compound is possibly a product of ascorbate catabolism (DeBolt et al. 2007). Pyrrole 2-carboxylate (\#16), also found in the algae, might be a chlorophyll catabolite, but it should be mentioned that chlorophyll degradation commonly stops at the stage of linear tetrapyrroles
(Hörtensteiner and Kräutler 2011). While 3-chloro-1,2-propanediol (\#7) was also detected, it is difficult to tell whether this compound really exists in $O$. tauri. Alternatively, it is possible that 3-chloro-1,2-propanediol was formed from the glycerol moiety of lipids during the derivatization procedure. We did not detect any sucrose in $O$. tauri.

\subsection{O. tauri metabolites showing diurnal fluctuations}

Figure 3 graphically depicts the temporal changes of the metabolites that correspond to the 111 quantifiable peaks. To identify diurnally oscillating compounds, we analyzed how the concentrations of the different metabolites varied over a light-dark cycle. For this purpose, the temporal patterns of all quantifiable peaks were grouped into clusters using a Bayesian Fourier clustering method, which was previously used for analyzing RNA microarray data (Monnier et al. 2010). The metabolites grouped into five clusters (Supplementary Fig. 1). The abundances of the metabolites from cluster 1 show no or only small fluctuations. Cluster 2 contains metabolites that are more abundant during the day, while clusters 3,4 and 5 contain metabolites that are more abundant during the night. In other words, 20 of 111
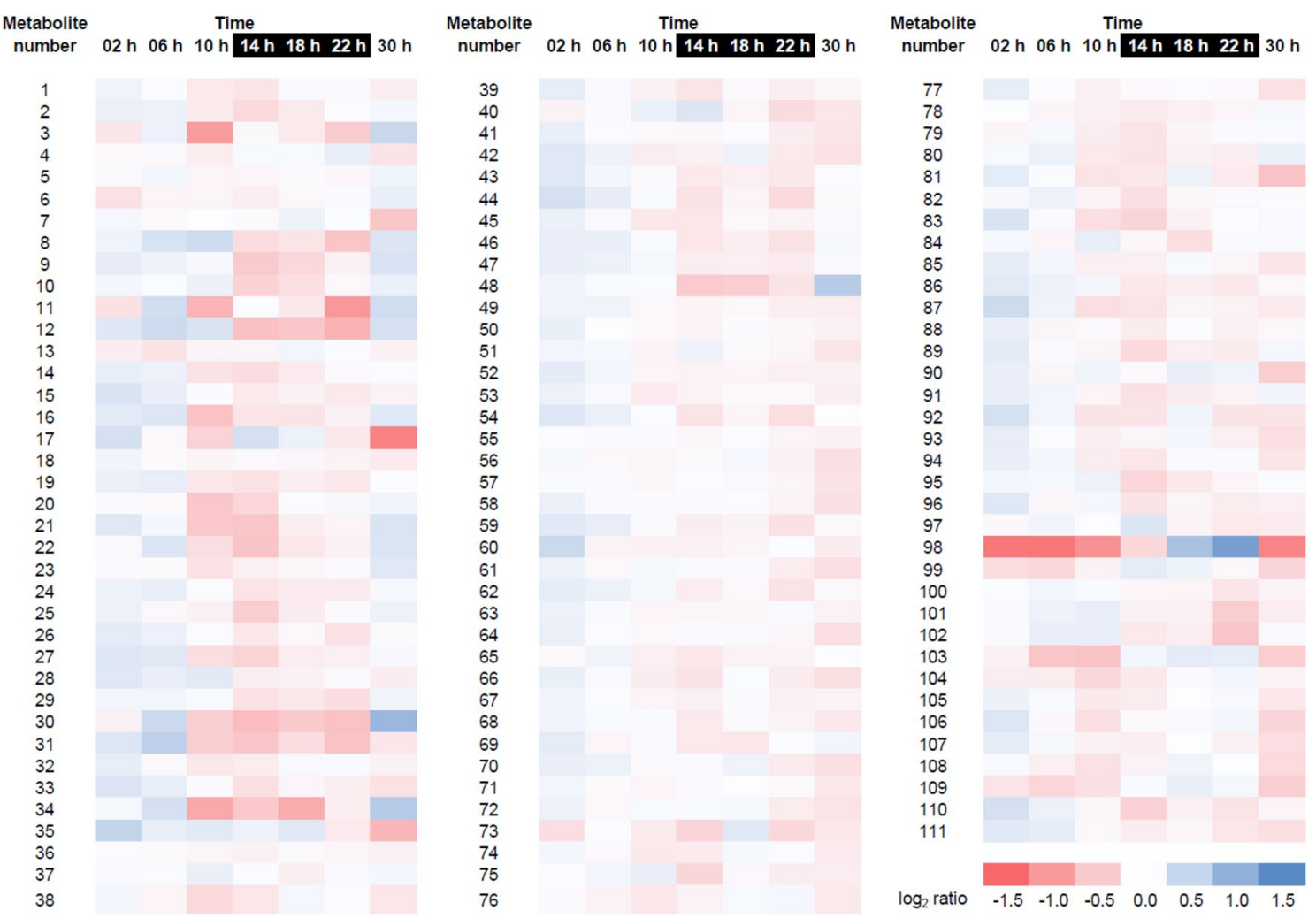

Fig. 3 Time course of $O$. tauri metabolite concentrations over a light-dark cycle (heat map). For the metabolites of 111 quantifiable peaks, $\log _{2}$ values of mean abundances were calculated and centered on zero. Blue indicates increased metabolite abundance, red indicates decreased abundance. The underlying sampling scheme is depicted in Fig. 2a, and the absolute values used to prepare this figure are provided in Supplementary Table 3 
metabolites (18\%) group into clusters with clear diurnal fluctuations.

Examples of diurnally fluctuating metabolites include glycine, which is up to 2.1-fold more abundant in the light than in darkness (Fig. 4a). Light accumulation of glycine (\#12), an intermediate of the photorespiratory pathway, was also reported for Arabidopsis thaliana (Gibon et al. 2006)

a

Glycine

$\left(t_{r}=8.24 \mathrm{~min}, \mathrm{~m} / \mathrm{z}\right.$ 174.2)
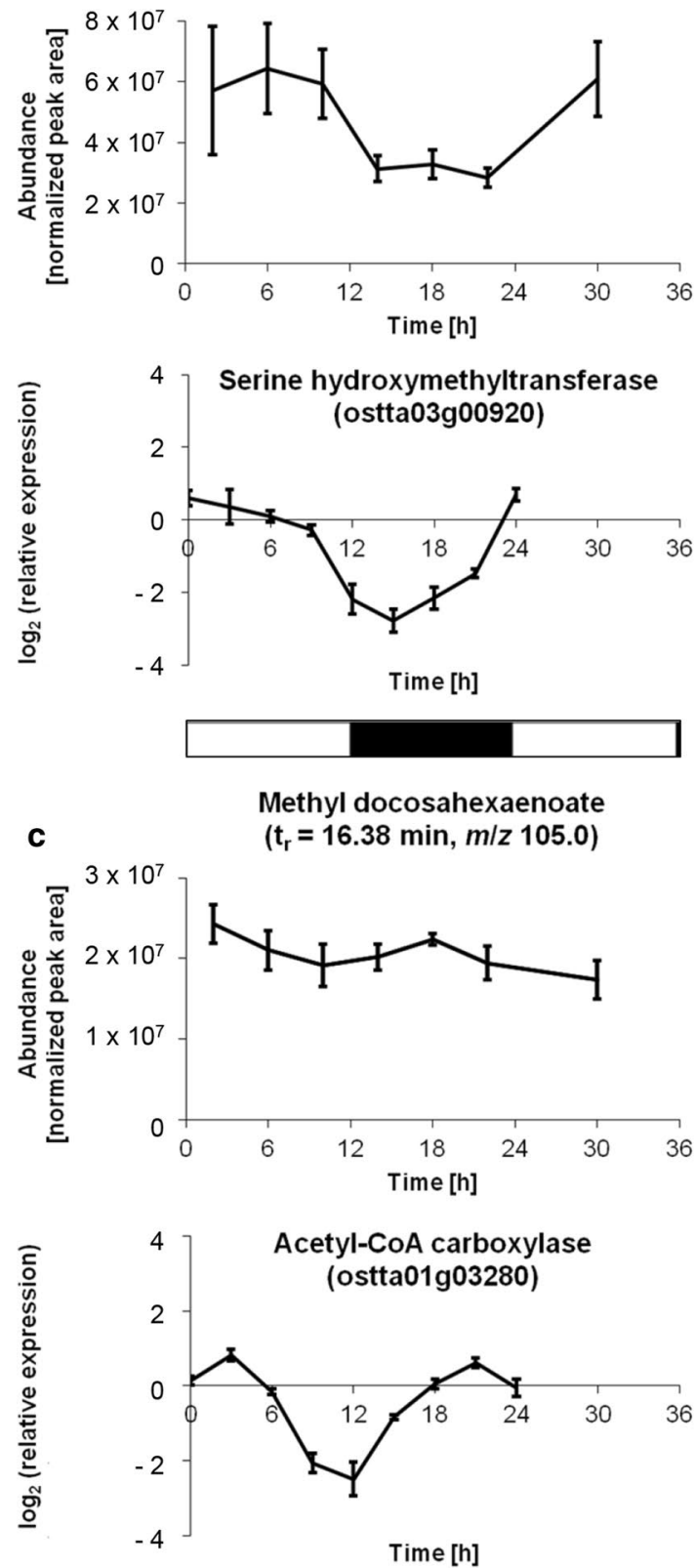

Fig. 4 Selected intracellular metabolites that show diurnal fluctuations in $O$. tauri. a Glycine (\#12). b Squalene (\#99). c Methyl docosahexaenoate (\#93). d Trehalose (\#98). For the metabolites, which were sampled according to the scheme shown in Fig. 2a, mean \pm standard deviation of four biological replicates is shown. Since a standard curve was measured for trehalose (Supplementary or the macroalga Ectocarpus siliculosus (Gravot et al. 2010). For comparison, transcriptome data from Monnier et al. 2010 were included in Fig. 4 for selected genes related to the metabolites shown. Of three genes predicted to encode serine hydroxymethyltransferase in $O$. tauri, the transcript levels of one gene parallel the levels of glycine (Fig. 4a) and may thus encode the isoform involved

b
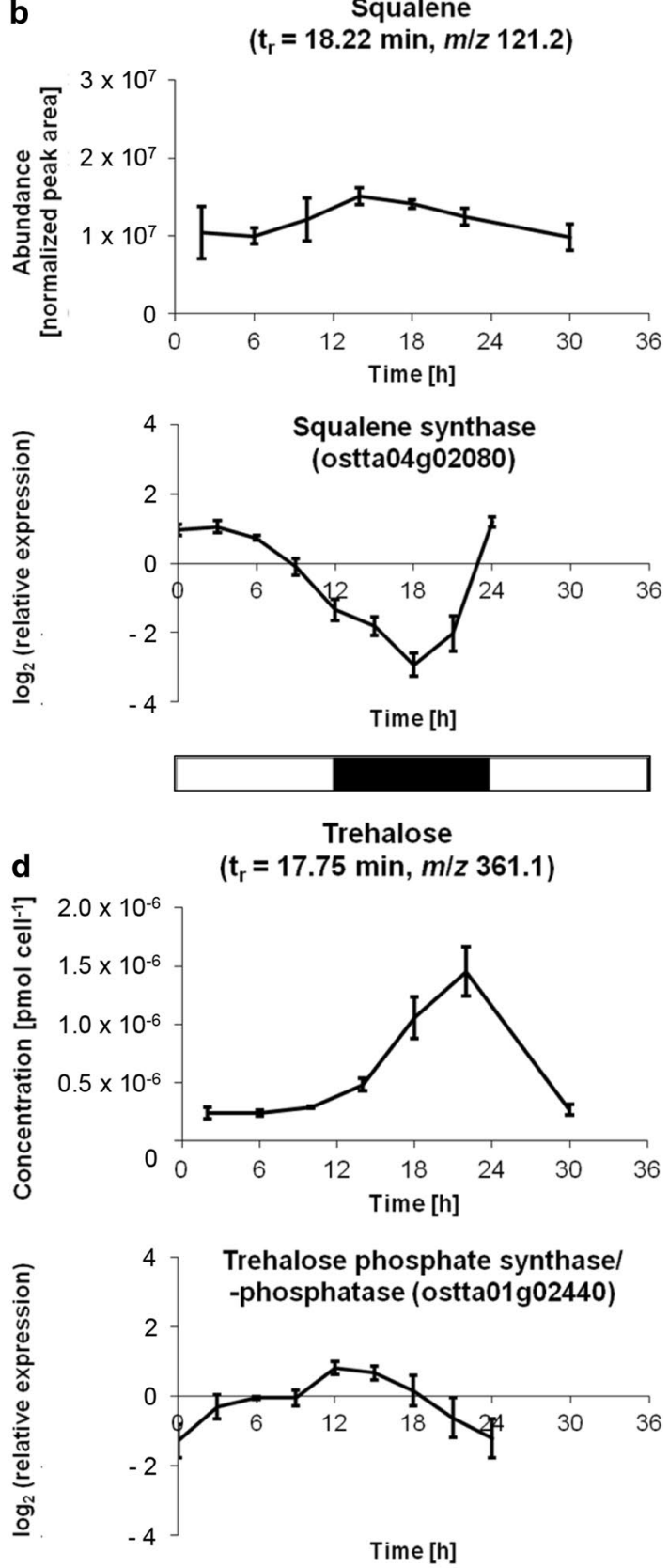

Fig. 2), the trehalose concentration is expressed in pmol cell ${ }^{-1}$. For comparison, transcript levels (taken from Monnier et al. 2010) are depicted for selected genes related to the respective metabolites. The identifiers of all genes mentioned in this work are listed in Supplementary Table 4 . The horizontal bars in the middle of the figure denote the light and dark phases (white and black areas, respectively) 
Fig. 5 Verification of trehalose in O. tauri. Shown are peaks from extracted ion chromatograms (EICs) representative of trehalose, maltose, or glucose. To unambiguously identify the disaccharide from $O$. tauri detected by GC-MS, an extract was treated with either trehalase or maltase. Only trehalase, but not maltase, efficiently hydrolyzed the disaccharide into glucose, showing that $O$. tauri produces trehalose. For comparison, standards of trehalose and maltose (enzyme-treated or untreated) and glucose are shown

in photorespiration. These data are in agreement with the presence of a classical glycolate pathway of photorespiration in $O$. tauri.

The abundance of squalene (\#99), the universal precursor of triterpenes including phytosterols, peaks in the early dark phase (Fig. 4b). This pattern contrasts with the transcript profile of the single squalene synthase gene, which is highest in the early light phase (Fig. 4b). Therefore, even though squalene synthase serves as the first committed step in triterpene biosynthesis, this maximal shift indicates that the transcript levels of the squalene synthase gene in $O$. tauri is a poor indicator for the levels of its enzymatic products.

The levels of the methyl ester of docosahexaenoic acid (DHA, C22:6) (\#93) reached a maximum at night (Fig. 4c). While the amplitude of this fluctuation is low, this pattern is similar to the daily patterns of other confirmed fatty acid esters (metabolite numbers 41, 61, 64, 71, 72 and 96; Fig. 3 and Supplementary Table 3 ). This profile roughly coincides with the transcript levels of the gene for the committed step of fatty acid biosynthesis (acetyl-CoA carboxylase), which features pronounced peaks at night and early morning (Fig. 4c). In contrast, many free fatty acids accumulate to some extent around dusk in A. thaliana, even though eicosenoate (C20:1), for example, peaks at night (Gibon et al. 2006).

Finally, we found the strongest fluctuations for trehalose (\#98), which is up to sixfold more abundant in the night compared to the day (Fig. 4d). The identity of this non-reducing disaccharide was confirmed with the help of authentic trehalose (Table 1).

\subsection{Trehalose accumulates to a concentration of $\sim 1.6 \mathrm{mM}$ at night}

Since the discovery of the strong day/night fluctuations of trehalose (Fig. 4d) in O. tauri was somewhat surprising, we aimed at further corroborating the identity of this metabolite. For example, maltose also consists of two glucose monomers and had a retention time ( 17.64 min) very similar to that of trehalose $(\sim 17.68 \mathrm{~min})$. We thus treated an extract of $O$. tauri with trehalase, which resulted in the complete disappearance of the trehalose peak and the concomitant appearance of the cleavage product glucose (Fig. 5). In contrast, treatment with maltase only resulted in

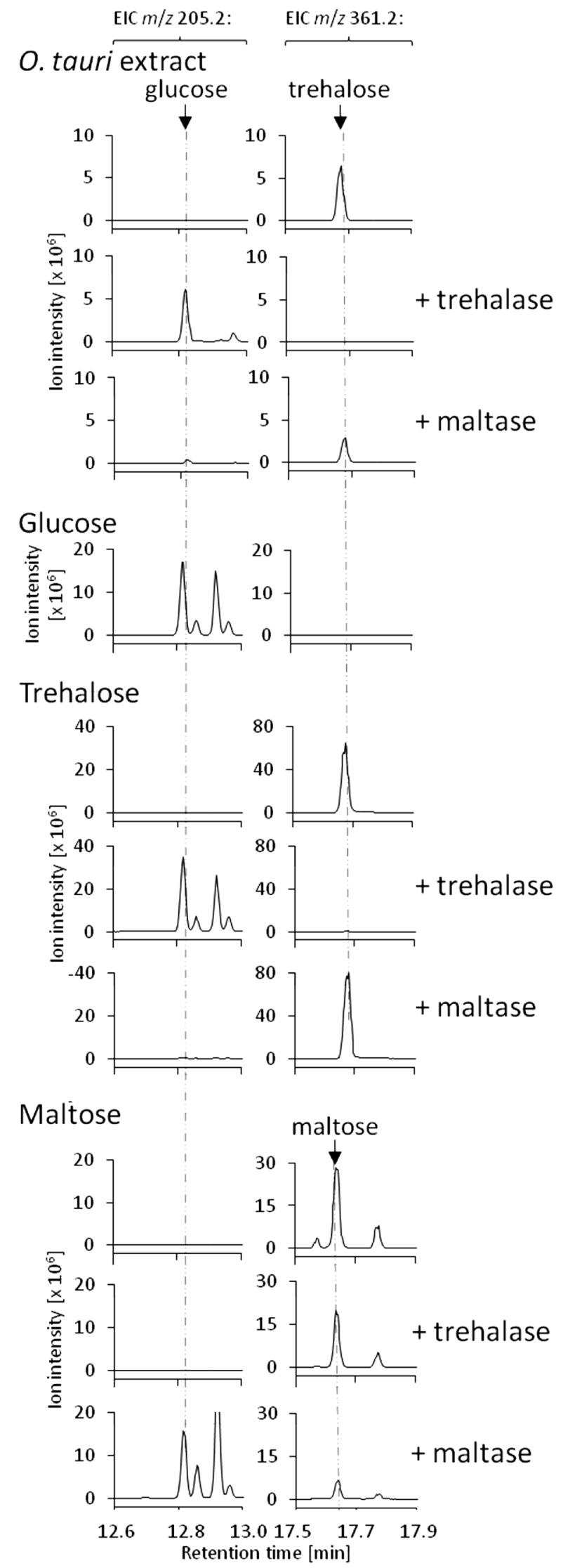


a minor amount of glucose (Fig. 5), further confirming that $O$. tauri indeed produces trehalose. As a control, authentic samples of trehalose and maltose were also treated with each of the two enzymes (Fig. 5).

To determine the absolute amounts of trehalose inside O. tauri cells, a standard curve was measured (Supplementary Fig. 2). Intracellular trehalose concentrations ranged from $0.23 \times 10^{-6} \mathrm{pmol} \mathrm{cell}^{-1}$ during the light phase to $1.45 \times 10^{-6} \mathrm{pmol} \mathrm{cell}^{-1}$ in the dark phase (Fig. 4d). Using an average cell volume of $0.91 \mu^{3}$, which was determined at the end of the dark phase (Henderson et al. 2007), the highest trehalose concentration is $1.60 \mathrm{mM}$. Since this calculation assumes a uniform intracellular distribution of trehalose, actual concentrations may even be higher if trehalose is accumulated in specific compartments. Taken together, we have found strong fluctuations of trehalose over light-dark cycles, which peak at night with millimolar concentrations.

\section{Discussion}

As a vitally important source of energy, light dominates many aspects in the lives of photosynthetic organisms. The adaptation of plant metabolism to diurnal cycles has been studied by quantitative metabolic profiling in several plants, including A. thaliana (Gibon et al. 2006), rice (Sato et al. 2008) and Nicotiana attenuata (Kim et al. 2011), and the brown alga E. siliculosus (Gravot et al. 2010). Under a photoperiod of $12 \mathrm{~h} \mathrm{light}$ and $12 \mathrm{~h}$ darkness, cells of the photosynthetic eukaryote $O$. tauri divide in a synchronized fashion at the end of the light phase or the beginning of the dark phase (Farinas et al. 2006). Using this light regime, we have quantified the levels of 111 metabolites in $O$. tauri using GC-MS. Since metabolic profiling was performed during late exponential/early stationary phase (Fig. 2a), a low rate of cell division and a relatively constant average cell volume are expected during our experiment. Supported by the use of standards, 25 metabolites were confirmed with high confidence (Table 1), and 49 additional metabolites were tentatively identified using database comparisons (Supplementary Table 2). A relatively high number of metabolites had low match values and remained unidentified (Supplementary Table 2). This may reflect the fact that the metabolism of $O$. tauri has been poorly characterized so far, and suggest the presence of a number of uncommon metabolites.

As in previous attempts of antibiotic treatment (Abby et al. 2014), we were unable to remove associated bacteria from $O$. tauri completely using an antibiotic cocktail or FACS. These observations might be explained by a physical association between algae and bacteria, but further work is required to investigate this possibility. The bacteria that remained in the culture after FACS sorting are expected to influence the metabolite profiles to some degree. We however conclude that removal of these apparently essential associated microbes would cause stress to $O$. tauri to a degree that its metabolome would essentially only reflect stress conditions and mask natural physiological responses. We therefore carried out our study with a substantially reduced load of associated bacteria and summarize the detected metabolites under the term $O$. tauri metabolome. The low content of bacteria at the point of metabolite sampling (below $0.1 \%$ of total cells) suggests only small contributions by the bacteria. It is evident that the presence of bacteria may affect the regulation of algal metabolism, and it will not be possible to quantify this effect until axenic cultures of $O$. tauri become available. In some cases, microbial communities even acquire the capacity for the biosynthesis of novel metabolites that cannot be produced by the individual microorganisms on their own (cooperative biosynthesis); so far however, only few examples of this phenomenon are known (Hom et al. 2015; Kusari et al. 2016).

Of the fatty acid esters identified in $O$. tauri, several were confirmed with the help of standards (Table 1). For example, we found both methyl palmitate (\#61) and ethyl palmitate (\#64, eluting $\sim 0.45$ min after methyl palmitate), whereas free palmitate could not be detected. Even when pure palmitic acid was dissolved in extraction mix (methanol:ethanol:chloroform 2:6:2) before derivatization, only the monosilylated derivative was detected by GC-MS (eluting $~ 0.31$ min after ethyl palmitate), but no alkyl esters. These findings suggest that $O$. tauri produces a range of fatty acid esters, even though we cannot rule out with complete certainty that the detected fatty acid esters were formed during the derivatization by esterification of free fatty acids or transesterification of lipid-bound fatty acids. Evidence for the biosynthesis of fatty acid esters also exists in Chlamydomonas reinhardtii (Herrera-Valencia et al. 2012), another chlorophyte distantly related to $O$. tauri.

With a sixfold peak-to-peak amplitude, trehalose showed the strongest fluctuation of all metabolites quantified in $O$. tauri grown under light-dark cycles (Fig. 4d). Similarly, $A$. thaliana produces a diurnally oscillating disaccharide that was not identified (Kim et al. 2011), but could be trehalose. Trehalose is made by all organisms except vertebrates (Paul et al. 2008). Plants generally use trehalose phosphate synthase (TPS) to convert glucose 6-phosphate and UDPglucose into trehalose 6-phosphate, which is then converted into trehalose by trehalose phosphatase (TPP) (Lunn et al. 2014). The genome of $O$. tauri encodes two bifunctional TPS-TPP versions (identifiers ostta01g02440 and ostta12g02400) and one monofunctional TPP (ostta14g00250) (Blanc-Mathieu et al. 2014). While the transcript of the 
monofunctional TPP is most abundant during the day, both bifunctional TPS-TPP genes are upregulated in the first half of the night (Fig. 4d and Supplementary Fig. 3), which is largely in agreement with a pathway that uses two monosaccharide building blocks to make trehalose. Our dataset does not allow for any statements on the levels of sugar phosphates such as trehalose 6-phosphate, possibly because their derivatives do not reach the mass spectrometer.

In plants and algae, trehalose and its precursor trehalose 6-phosphate have been implicated in a variety of functions ranging from carbon storage to the regulation of carbon metabolism, the protection from osmotic stress and other forms of stress, or signaling in plant-microbe interactions (Paul et al. 2008; Lunn et al. 2014; Michel et al. 2010). In vascular plants, the function of trehalose as a stress protectant has been replaced by sucrose (Lunn et al. 2014). In Saccharomyces cerevisiae, trehalose is a key factor that enables survival to long-term desiccation (Tapia and Koshland 2014). Since $O$. tauri can cope with a wide range of salinities ranging from 5 to $65 \%$ (F.-Y. Bouget, unpublished results), it is possible, for example, that trehalose enhances the survival of this marine alga under hyperosmotic stress. Accumulation of trehalose in $O$. tauri during the dark phase might be triggered by starch degradation. As in other plants and algae, starch is built up by $O$. tauri in the light until it reaches a maximum at dusk, and is then used as a source of energy and carbon in the night (Sorokina et al. 2011). In vascular plants, high levels of trehalose 6-phosphate increase the rate of starch biosynthesis via redox activation of ADP-glucose pyrophosphorylase (Kolbe et al. 2005). However, the observation that ADP-glucose pyrophosphorylase from $O$. tauri is not redox-regulated (Kuhn et al. 2009) argues against such a function of trehalose 6-phosphate in this alga. With an average intracellular concentration of $1.6 \mathrm{mM}$, trehalose reaches its highest concentration at the end of the night (Fig. 4d). This apparent delay compared to the starch peak may suggest that trehalose accumulation is a consequence of starch degradation. Based on a prediction by the program PredAlgo (Tardif et al. 2012), the trehalose-forming enzymes mentioned above are localized in either chloroplast (ostta01g02440) or cytosol (ostta12g02400 and ostta14g00250), which is consistent with such a scenario. A connection between trehalose accumulation and starch degradation is further supported by the apparent absence of trehalose from E. siliculosus (Gravot et al. 2010), which does not produce starch (Michel et al. 2010).

In contrast to the major products of starch degradation, the reducing sugars maltose and glucose (Streb and Zeeman 2012), trehalose is a non-reducing sugar and thus less reactive. In our analysis, maltose was not detected in any of the samples (Fig. 5 and data not shown). Based on an estimated detection limit of $\sim 0.2 \mathrm{pmol}$, the intracellular concentration of maltose is below $\sim 10 \mu \mathrm{M}$. It is plausible that $O$. tauri produces trehalose to prevent excessive amounts of reactive starch degradation products, with trehalose functioning as a temporary buffer of carbon and energy during starch degradation. Alternatively, the diurnal fluctuation of trehalose may be a consequence of the synchronized cell cycle. In $S$. cerevisiae, maximal intracellular trehalose concentrations were detected at the G1/S transition (Ewald et al. 2016). When trehalose peaks at the end of the dark phase (Fig. 4d), O. tauri is in the middle of the G1 phase (Farinas et al. 2006). Further investigations of the function of trehalose in $O$. tauri will be greatly supported by the generation and characterization of trehalose biosynthesis mutants.

Acknowledgements We are grateful to Katharina Eick, Constanze Kuhlisch and Christine Lembke (Friedrich Schiller University, Jena) for help with GC-MS and subsequent data analysis, and to Andrea Völpel, Yvonne Schlenker, Prof. Bernd Sigusch, and Dr. Martin Förster (University Hospital, Jena) for help with flow cytometry and access to their instruments. M.H. and S.S. acknowledge financial support by the Jena School for Microbial Communication (GSC 214/2), which is funded by the German Research Foundation (DFG). G.P. and S.S. are supported by the DFG-funded Collaborative Research Centre ChemBioSys (SFB 1127).

\section{Compliance with ethical standards}

Conflict of interest All authors (Matthias Hirth, Silvia Liverani, Sebastian Mahlow, François-Yves Bouget, Georg Pohnert, Severin Sasso) declare that there is no conflict of interest.

Research involving human participants and/or animals No human participants or animals were involved in this study.

Informed consent No human participants were involved in this study.

Open Access This article is distributed under the terms of the Creative Commons Attribution 4.0 International License (http:// creativecommons.org/licenses/by/4.0/), which permits unrestricted use, distribution, and reproduction in any medium, provided you give appropriate credit to the original author(s) and the source, provide a link to the Creative Commons license, and indicate if changes were made.

\section{References}

Abby, S. S., Touchon, M., De Jode, A., Grimsley, N., \& Piganeau, G. (2014). Bacteria in Ostreococcus tauri cultures-friends, foes or hitchhikers? Frontiers in Microbiology, 5, 505.

Amin, S. A., Parker, M. S., \& Armbrust, E. V. (2012). Interactions between diatoms and bacteria. Microbiology and Molecular Biology Reviews, 76(3), 667-684.

Blanc-Mathieu, R., Sanchez-Ferandin, S., Eyre-Walker, A., \& Piganeau, G. (2013). Organellar inheritance in the green lineage: Insights from Ostreococcus tauri. Genome Biology and Evolution, 5(8), 1503-1511.

Blanc-Mathieu, R., Verhelst, B., Derelle, E., Rombauts, S., Bouget, F.-Y., Carré, I., et al. (2014). An improved genome of the model 
marine alga Ostreococcus tauri unfolds by assessing Illumina de novo assemblies. BMC Genomics, 15, 1103.

Botebol, H., Lesuisse, E., Šuták, R., Six, C., Lozano, J.-C., Schatt, P., et al. (2015). Central role for ferritin in the day/night regulation of iron homeostasis in marine phytoplankton. Proceedings of the National Academy of Sciences of the United States of America, 112(47), 14652-14657.

Broeckling, C. D., Reddy, I. R., Duran, A. L., Zhao, X., \& Sumner, L. W. (2006). MET-IDEA: Data extraction tool for mass spectrometry-based metabolomics. Analytical Chemistry, 78(13), 4334-4341.

Cardol, P., Bailleul, B., Rappaport, F., Derelle, E., Béal, D., Breyton, C., et al. (2008). An original adaptation of photosynthesis in the marine green alga Ostreococcus. Proceedings of the National Academy of Sciences of the United States of America, 105(22), 7881-7886.

Chrétiennot-Dinet, M.-J., Courties, C., Vaquer, A., Neveux, J., Claustre, H., Lautier, J., et al. (1995). A new marine picoeukaryote: Ostreococcus tauri, gen. et sp. nov. (Chlorophyta, Prasinophyceae). Phycologia, 34(4), 285-292.

Collado-Fabbri, S., Vaulot, D., \& Ulloa, O. (2011). Structure and seasonal dynamics of the eukaryotic picophytoplankton community in a wind-driven coastal upwelling ecosystem. Limnology and Oceanography, 56(6), 2334-2346.

Corellou, F., Schwartz, C., Motta, J.-P., Djouani-Tahri, E. B., Sanchez, F., \& Bouget, F.-Y. (2009). Clocks in the green lineage: Comparative functional analysis of the circadian architecture of the picoeukaryote Ostreococcus. The Plant Cell, 21(11), 3436-3449.

Courties, C., Vaquer, A., Trousselier, M., Lautier, J., ChrétiennotDinet, M. J., Neveux, J., et al. (1994). Smallest eukaryotic organism. Nature, 370(6487), 255.

DeBolt, S., Melino, V., \& Ford, C. M. (2007). Ascorbate as a biosynthetic precursor in plants. Annals of Botany, 99(1), 3-8.

Derelle, E., Ferraz, C., Escande, M.-L., Eychenié, S., Cooke, R., Piganeau, G., et al. (2008). Life-cycle and genome of OtV5, a large DNA virus of the pelagic marine unicellular green alga Ostreococcus tauri. PLoS ONE, 3(5), e2250.

Derelle, E., Ferraz, C., Rombauts, S., Rouzé, P., Worden, A. Z., Robbens, S., et al. (2006). Genome analysis of the smallest free-living eukaryote Ostreococcus tauri unveils many unique features. Proceedings of the National Academy of Sciences of the United States of America, 103(31), 11647-11652.

Djouani-Tahri, E. B., Christie, J. M., Sanchez-Ferandin, S., Sanchez, F., Bouget, F.-Y., \& Corellou, F. (2011a). A eukaryotic LOVhistidine kinase with circadian clock function in the picoalga Ostreococcus. Plant Journal, 65(4), 578-588.

Djouani-Tahri, E. B., Sanchez, F., Lozano, J.-C., \& Bouget, F.-Y. (2011b). A phosphate-regulated promoter for fine-tuned and reversible overexpression in Ostreococcus: Application to circadian clock functional analysis. PLOS ONE, 6(12), e28471.

Ewald, J. C., Kuehne, A., Zamboni, N., \& Skotheim, J. M. (2016). The yeast cyclin-dependent kinase routes carbon fluxes to fuel cell cycle progression. Molecular Cell, 61(4), 532-545.

Falkowski, P. G., Barber, R. T., \& Smetacek, V. (1998). Biogeochemical controls and feedbacks on ocean primary production. Science, 281(5374), 200-206.

Farinas, B., Mary, C., de O Manes, C.-L., Bhaud, Y., Peaucellier, G., \& Moreau, H. (2006). Natural synchronisation for the study of cell division in the green unicellular alga Ostreococcus tauri. Plant Molecular Biology, 60(2), 277-292.

Gibon, Y., Usadel, B., Blaesing, O. E., Kamlage, B., Hoehne, M., Trethewey, R., et al. (2006). Integration of metabolite with transcript and enzyme activity profiling during diurnal cycles in Arabidopsis rosettes. Genome Biology, 7(8), R76.

Gravot, A., Dittami, S. M., Rousvoal, S., Lugan, R., Eggert, A., Collén, J., et al. (2010). Diurnal oscillations of metabolite abundances and gene analysis provide new insights into central metabolic processes of the brown alga Ectocarpus siliculosus. New Phytologist, 188(1), 98-110.

Grimsley, N., Péquin, B., Bachy, C., Moreau, H., \& Piganeau, G. (2010). Cryptic sex in the smallest eukaryotic marine green alga. Molecular Biology and Evolution, 27(1), 47-54.

Hansen, H. P., \& Koroleff, F. (1999). Determination of nutrients. In K. Grasshoff, K. Kremling \& M. Ehrhardt (Eds.), Methods of seawater analysis. Weinheim: Wiley-VCH.

Heijde, M., Zabulon, G., Corellou, F., Ishikawa, T., Brazard, J., Usman, A., et al. (2010). Characterization of two members of the cryptochrome/photolyase family from Ostreococcus tauri provides insights into the origin and evolution of cryptochromes. Plant Cell and Environment, 33(10), 1614-1626.

Henderson, G. P., Gan, L., \& Jensen, G. J. (2007). 3-D ultrastructure of $O$. tauri: Electron cryotomography of an entire eukaryotic cell. PLoS ONE, 2(8), e749.

Herrera-Valencia, V. A., Us-Vázquez, R. A., Larqué-Saavedra, F. A., \& Barahona-Pérez, L. F. (2012). Naturally occurring fatty acid methyl esters and ethyl esters in the green microalga Chlamydomonas reinhardtii. Annals of Microbiology, 62(2), 865-870.

Hom, E. F. Y., Aiyar, P., Schaeme, D., Mittag, M., \& Sasso, S. (2015). A chemical perspective on microalgal-microbial interactions. Trends in Plant Science, 20(11), 689-693.

Hörtensteiner, S., \& Kräutler, B. (2011). Chlorophyll breakdown in higher plants. Biochimica et Biophysica Acta, 1807(8), 977-988.

Keller, M. D., Selvin, R. C., Claus, W., \& Guillard, R. R. L. (1987). Media for the culture of oceanic ultraphytoplankton. Journal of Phycology, 23(4), 633-638.

Kim, S.-G., Yon, F., Gaquerel, E., Gulati, J., \& Baldwin, I. T. (2011) Tissue specific diurnal rhythms of metabolites and their regulation during herbivore attack in a native tobacco, Nicotiana attenuata. PLoS ONE, 6(10), e26214.

Kolbe, A., Tiessen, A., Schluepmann, H., Paul, M., Ulrich, S., \& Geigenberger, P. (2005). Trehalose 6-phosphate regulates starch synthesis via posttranslational redox activation of ADP-glucose pyrophosphorylase. Proceedings of the National Academy of Sciences of the United States of America, 102(31), 11118-11123.

Kuhn, M. L., Falaschetti, C. A., \& Ballicora, M. A. (2009). Ostreococcus tauri ADP-glucose pyrophosphorylase reveals alternative paths for the evolution of subunit roles. Journal of Biological Chemistry, 284(49), 34092-34102.

Kusari, P., Kusari, S., Eckelmann, D., Zühlke, S., Kayser, O., \& Spiteller, M. (2016). Cross-species biosynthesis of maytansine in Maytenus serrata. RSC Advances, 6(12), 10011-10016.

Lee, M. L., Vassilaros, D. L., White, C. M., \& Novotny, M. (1979). Retention indices for programmed-temperature capillary-column gas chromatography of polycyclic aromatic hydrocarbons. Analytical Chemistry, 51(6), 768-773.

Lelandais, G., Scheiber, I., Paz-Yepes, J., Lozano, J.-C., Botebol, H., Pilátová, J., et al. (2016). Ostreococcus tauri is a new model green alga for studying iron metabolism in eukaryotic phytoplankton. BMC Genomics, 17, 319.

Leliaert, F., Smith, D. R., Moreau, H., Herron, M. D., Verbruggen, H., Delwiche, C. F., et al. (2012). Phylogeny and molecular evolution of the green algae. Critical Reviews in Plant Sciences, $31(1), 1-46$.

Li, W. K. W. (1994). Primary production of prochlorophytes, cyanobacteria, and eukaryotic ultraphytoplankton: Measurements from flow cytometric sorting. Limnology and Oceanography, 39(1), 169-175.

Lozano, J.-C., Schatt, P., Botebol, H., Vergé, V., Lesuisse, E., Blain, S., et al. (2014). Efficient gene targeting and removal of foreign DNA by homologous recombination in the picoeukaryote Ostreococcus. Plant Journal, 78(6), 1073-1083. 
Lunn, J. E., Delorge, I., Figueroa, C. M., Van Dijck, P., \& Stitt, M. (2014). Trehalose metabolism in plants. Plant Journal, 79(4), 544-567.

Lupette, J., Lami, R., Krasovec, M., Grimsley, N., Moreau, H., Piganeau, G., et al. (2016). Marinobacter dominates the bacterial community of the Ostreococcus tauri phycosphere in culture. Frontiers in Microbiology, 7, 1414.

Michel, G., Tonon, T., Scornet, D., Cock, J. M., \& Kloareg, B. (2010). Central and storage carbon metabolism of the brown alga Ectocarpus siliculosus: Insights into the origin and evolution of storage carbohydrates in eukaryotes. New Phytologist, 188(1), $67-81$.

Monnier, A., Liverani, S., Bouvet, R., Jesson, B., Smith, J. Q., Mosser, J., et al. (2010). Orchestrated transcription of biological processes in the marine picoeukaryote Ostreococcus exposed to light/dark cycles. BMC Genomics, 11, 192.

Moulager, M., Corellou, F., Vergé, V., Escande, M.-L., \& Bouget, F.-Y. (2010). Integration of light signals by the retinoblastoma pathway in the control of S phase entry in the picophytoplanktonic cell Ostreococcus. PLoS Genetics, 6(5), e1000957.

O’Kelly, C. J., Sieracki, M. E., Thier, E. C., \& Hobson, I. C. (2003). A transient bloom of Ostreococcus (Chlorophyta, Prasinophyceae) in West Neck Bay, Long Island, New York. Journal of Phycology, 39(5), 850-854.

O'Neill, J. S., van Ooijen, G., Dixon, L. E., Troein, C., Corellou, F., Bouget, F.-Y., et al. (2011). Circadian rhythms persist without transcription in a eukaryote. Nature, 469(7331), 554-558.

Paerl, R. W., Bouget, F.-Y., Lozano, J.-C., Vergé, V., Schatt, P., Allen, E. E., et al. (2017). Use of plankton-derived vitamin $B_{1}$ precursors, especially thiazole-related precursor, by key marine picoeukaryotic phytoplankton. ISME Journal, 11(3), 753-765.

Paul, M. J., Primavesi, L. F., Jhurreea, D., \& Zhang, Y. (2008). Trehalose metabolism and signaling. Annual Review of Plant Biology, $59,417-441$

Ramanan, R., Kim, B.-H., Cho, D.-H., Oh, H.-M., \& Kim, H.-S. (2016). Algae-bacteria interactions: Evolution, ecology and emerging applications. Biotechnology Advances, 34(1), 14-29.

Rodríguez, F., Derelle, E., Guillou, L., Le Gall, F., Vaulot, D., \& Moreau, H. (2005). Ecotype diversity in the marine picoeukaryote Ostreococcus (Chlorophyta, Prasinophyceae). Environmental Microbiology, 7(6), 853-859.
Sato, S., Arita, M., Soga, T., Nishioka, T., \& Tomita, M. (2008). Time-resolved metabolomics reveals metabolic modulation in rice foliage. BMC Systems Biology, 2, 51.

Smith, A. G., Croft, M. T., Moulin, M., \& Webb, M. E. (2007). Plants need their vitamins too. Current Opinion in Plant Biology, 10(3), 266-275.

Sorokina, O., Corellou, F., Dauvillée, D., Sorokin, A., Goryanin, I., Ball, S., et al. (2011). Microarray data can predict diurnal changes of starch content in the picoalga Ostreococcus. BMC Systems Biology, 5, 36.

Streb, S., \& Zeeman, S. C. (2012). Starch metabolism in Arabidopsis. The Arabidopsis Book, 10, $\mathrm{e} 0160$.

Tapia, H., \& Koshland, D. E. (2014). Trehalose is a versatile and long-lived chaperone for desiccation tolerance. Current Biology, 24(23), 2758-2766.

Tardif, M., Atteia, A., Specht, M., Cogne, G., Rolland, N., Brugière, S., et al. (2012). PredAlgo: A new subcellular localization prediction tool dedicated to green algae. Molecular Biology and Evolution, 29(12), 3625-3639.

Vaezi, R., Napier, J. A., \& Sayanova, O. (2013). Identification and functional characterization of genes encoding omega- 3 polyunsaturaed fatty acid biosynthetic activities from unicellular microalgae. Marine Drugs, 11(12), 5116-5129.

Vaulot, D., Eikrem, W., Viprey, M., \& Moreau, H. (2008). The diversity of small eukaryotic phytoplankton $(<=3 \mu \mathrm{m})$ in marine ecosystems. FEMS Microbiology Reviews, 32(5), 795-820.

Vidoudez, C., \& Pohnert, G. (2012). Comparative metabolomics of the diatom Skeletonema marinoi in different growth phases. Metabolomics, 8(4), 654-669.

Weirauch, M. T., Yang, A., Albu, M., Cote, A. G., MontenegroMontero, A., Drewe, P., et al. (2014). Determination and inference of eukaryotic transcription factor sequence specificity. Cell, 158(6), 1431-1443.

Worden, A. Z., Follows, M. J., Giovannoni, S. J., Wilken, S., Zimmerman, A. E., \& Keeling, P. J. (2015). Rethinking the marine carbon cycle: Factoring in the multifarious lifestyles of microbes. Science, 347(6223), 1257594.

Worden, A. Z., Nolan, J. K., \& Palenik, B. (2004). Assessing the dynamics and ecology of marine picophytoplankton: The importance of the eukaryotic component. Limnology and Oceanography, 49(1), 168-179. 